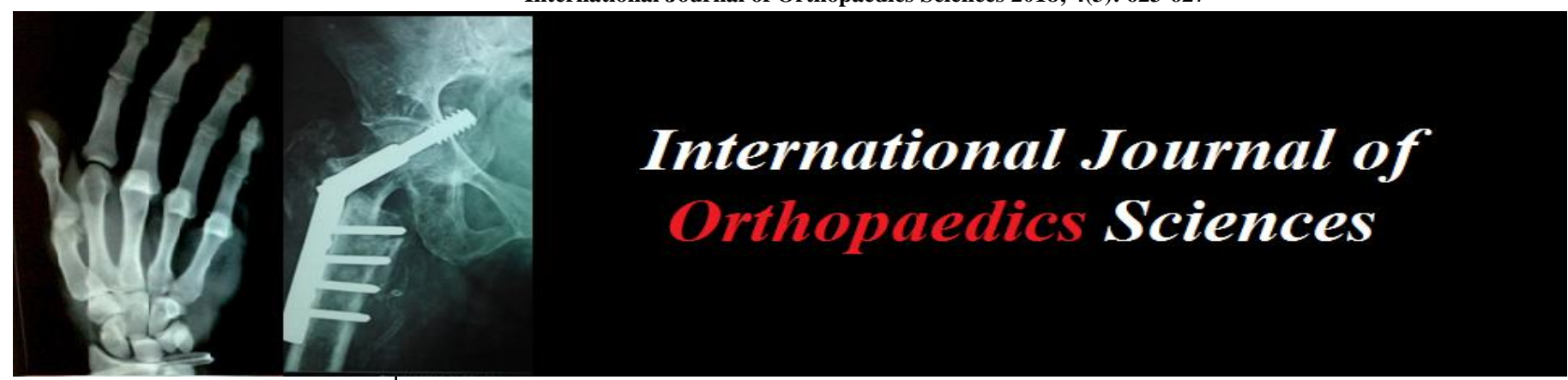

ISSN: $2395-1958$

IJOS 2018; 4(3): 623-627

(C) 2018 IJOS

www.orthopaper.com

Received: 19-05-2018

Accepted: 20-06-2018

Kumar Surendra

Assistant Professor,

Department of Orthopaedics

BRD Medical College,

Gorakhpur, Uttar Pradesh, India

Yadav Ashok

Assistant Professor,

Department of Orthopaedics

BRD Medical College,

Gorakhpur, Uttar Pradesh, India

Chaudhary Sanjay

Assistant Professor,

Department of Orthopaedics

BRD Medical College,

Gorakhpur, Uttar Pradesh, India

Tomar Shashank

Department of Orthopaedics

BRD Medical College,

Gorakhpur, Uttar Pradesh, India

Correspondence

Kumar Surendra

Assistant Professor,

Department of Orthopaedics

BRD Medical College,

Gorakhpur, Uttar Pradesh, India

\section{Functional assessment of tibial plateau fracture by various modalities of treatment}

\author{
Kumar Surendra, Yadav Ashok, Chaudhary Sanjay and Tomar Shashank
}

DOI: https://doi.org/10.22271/ortho.2018.v4.i3k.109

\section{Abstract}

Background: Tibial plateau is the most important weight bearing surface. These intraarticular fractures are difficult to treat and presented with different fracture morphology. Due to in-crease in incidence of high velocity trauma and higher functional demands of patients, surgery is indicated in most of the cases. Even though, there is advancement in fracture fixation methods, treatment of tibial plateau fractures still remains controversial.

Methods: In our series, we analyzed the functional outcomes of 18 of surgically treated tibial plateau fractures. Fractures were classified with Schatzker's classification. Various fixation modalities of fixation were employed. Functional outcome was evaluated with modified Rasmussen's criteria.

Results: The functional outcome assessment according to Modified Rasmussen's criteria at the end of 12 months showed the excellent functional outcome in 5 (27.7\%), good in eight $(44.4 \%)$, fair in four $(22.2 \%)$ and poor in one $(5.6 \%)$ patients.

Conclusions: Road traffic accidents are the main cause of injury with males affected more commonly than females. CT scan with three dimensional reconstructions gives accurate fracture geometry for preoperative planning for osteo-synthesis. Result of various types surgeries are good for various types of fracture pattern except when complications developed in elderly patients of type VI fracture pattern in the form of stiffness which led to an unacceptable outcome.

Keywords: Tibial plateau fracture, various modalities

\section{Introduction}

\section{Need for Study}

Tibial plateau fractures have been studied and reported extensively and exhaustively but still controversy exists over its management, whether surgical or conservative. Excellent results have been published in both groups. On one hand, we have got a group of surgeons who says that most of the tibial plateau fractures [eighty-five percent] can be managed by conservative treatment and on the other hand, other group says conservative treatment means therapeutic nihilism and except for undisplaced fracture every tibial plateau fracture should be operated upon to achieve anatomical reduction and rigid internal fixation. Even undisplaced tibial plateau fractures should be operated, so that early mobilization of knee it is possible.

\section{Material and Methods}

Source of Data

This is a study of patiets with tibial plateau fractures admitted in the Orthopaedics ward in B. R. D. Medical College, Gorakhpur, meeting both inclusion and exclusion criteria. For the patients with tibial plateau fracture who came to our hospital, preoperatively history was taken regarding mode of injury, time of injury, personal history, and treatment history and documented. Work up was done for surgical management. Consent was taken from all the patients. This prospective randomized study was analyzed. This study was done after approval from the Ethical Committee of our hospital.

\section{Selection criteria}

Inclusion criteria

1. Intra-articular fracture 
2. Age above 18 years and less than 60 years

3. Patients who are medically fit for surgery

4. Undisplaced type I tibial plateau fractures managed conservatively.

5. Open compound grade one fractures

\section{Exclusion Criteria}

1. Pathological fracture.

2. All open fractures excluding grade one fractures

3. Patients who are medically unfit and not willing for surgery

4. Fractures of the tibial plateau needing vascular repair

5. Refusal to provide informed consent

\section{Method}

In the prospective study of 18 cases depression more than 2-4 $\mathrm{mm}$ or split in either saggital or coronal plane was indication for surgery. Computerized Tomographic evaluation was done in cases which had more comminution and when x-ray was inconclusive, and MRI was done in suspected ligamentous and soft tissue injuries. All of the cases in this study were treated operatively as articular surface reconstruction was the main consideration. There was no strict surgical protocol followed in treating these cases. Most of the cases were operated within 7 days of admission.

\section{Implants used for internal fixation of tibial condylar fracture \\ Butresss plate}

The widening ends of long bone consist of large amount of cancellous bone. Such bone is comparatively weaker and has tendency of axial deviation or bending under the effect of compressive or shearing force. A lag screw cannot prevent the deformity and in order to supplement the fixation a buttress plate is essential to prevent collapse.

\section{Locking compression plate}

Locking compression plates are indicated for certain high energy bicondylar fractures, those with severe communition and in osteoporotic fractures. Laterally based locking plate offers an alternative to an additional medial plate or external fixator for support of the medial column in bicondylar fractures. Inter-fragmentary compression cannot be achieved by locked plates; supplementary use of inter-fragmentary screws may be required to prevent loss of reduction and to ensure adequate compression of the fragment.

\section{Screws}

1. Cortical screws $-4.5 \mathrm{~mm}$ diameter of various lengths

2. Cancellous screws:- $16 \mathrm{~mm}, 32 \mathrm{~mm}$ partially threaded and fully threaded

3. Locking screws

Cortical screws have a thick core with narrow thread and are used for purchase in cortical bone

\section{Operative protocols}

\section{Central depression fracture}

A window is made in the metaphyseal area below the depressed fragment, the depressed fragment elevated and autogenous cortico-cancellous bone graft packed beneath. Autogenous bone graft was harvested from the anterior aspect of the iliac crest. Fragment and graft were stabilized with cancellous screws or plate fixation.

\section{Split and Depressed Fracture}

Surgical intervention is necessary in a fracture more than 2-4 $\mathrm{mm}$ spilt and depressed. The depressed fragment is elevated and autogenous bone grafts from iliac crest are put and split is reduced and reduction is held with Kirschner wires. The fragments are then fixed with suitable plates and cancellous and cortical screws.

\section{Total Condylar Depression}

Fracture of medial or lateral condyle needs appropriate reduction as malunion may develop with varus or valgus malaligment. The depressed plateau is elevated, articular surface reconstructed and fixed with buttress plate

\section{Bicondylar Fractures}

Two incision technique is used for reduction of both the condyles. Arthrotomy is done for inspection of ligament injury or meniscal injury. Menisectomy done if indicated. Depending upon communition fixation is done by $\mathrm{L}, \mathrm{T}$ or hockey stick plate or locked plates and cancellous screws. Dual plating can be done if other side is unstable where collapse may occur.

\section{Post-Operative Care}

The patients with stable fixation were allowed intermittent knee mobilization once the wound pain subsided, early in type I, II and III in 5 to 10 days and late in type V and VI in 14 days or later depending upon communition of fracture.

Knee immobilization with brace or above knee cast was used in cases with ligamentous injuries for 4 to 6 weeks.

Weight bearing is deferred until evidence of union is seen on $\mathrm{x}$-rays (usual by 14 -16 weeks)

The patient was followed up at 6 weeks, 3 month, 6 month and 1 year. Partial weight bearing was started from 10- 14 weeks depending upon the fracture configuration and correlation with the $\mathrm{x}$-ray. Full range of motion is expected at 8-10 weeks after discharge.

\section{Observations}

\section{Distribution of fracture pattern}

\begin{tabular}{|c|c|c|}
\hline Type of fracture & No. of patients & Percentage \\
\hline I & 1 & $5.6 \%$ \\
\hline II & 3 & $16.6 \%$ \\
\hline III & 2 & $11.1 \%$ \\
\hline IV & 4 & $22.2 \%$ \\
\hline V & 3 & $16.6 \%$ \\
\hline VI & 5 & $27.7 \%$ \\
\hline
\end{tabular}

Majority of the cases from this study were type VI (27.7\%), and next was type IV (22.2\%)

\section{Modalities of treatment}

\begin{tabular}{|cl|c|c|}
\hline \multicolumn{2}{|c|}{ Method of treatment } & No of cases & Percentage \\
\hline 1. & PCCS & 1 & $5.6 \%$ \\
\hline 2. & ORIF with BP & 9 & $50 \%$ \\
\hline 3. & ORIF with BP + BG & 5 & $27.7 \%$ \\
\hline 4. & ORIF with BP+CCS & 1 & $5.6 \%$ \\
\hline 5. & ORIF with LP & 1 & $5.6 \%$ \\
\hline 6. & ORIF with LP+CCS & 1 & $5.6 \%$ \\
\hline
\end{tabular}

\section{Knee movement}

\begin{tabular}{|c|c|}
\hline$>120$ degree & 5 \\
\hline $90-120$ degree & 12 \\
\hline$<90$ degree & 1 \\
\hline
\end{tabular}




\section{Complications}

\begin{tabular}{|c|c|c|}
\hline & No. of patients & Percentage \\
\hline Pain & 5 & $27.7 \%$ \\
\hline Infection & 0 & - \\
\hline ROM $<90$ degree & 1 & $5.6 \%$ \\
\hline Varus & 1 & $5.6 \%$ \\
\hline Delayed union & 1 & $5.6 \%$ \\
\hline None & 10 & $56.6 \%$ \\
\hline
\end{tabular}

\section{Clinical Assessment}

\begin{tabular}{|c|c|c|}
\hline Result & No. of patients & Percentage \\
\hline Excellent & 8 & $44.4 \%$ \\
\hline Good & 7 & $38.8 \%$ \\
\hline Fair & 2 & $11.1 \%$ \\
\hline Poor & 1 & $5.6 \%$ \\
\hline
\end{tabular}

\section{Radiological Assessment}

\begin{tabular}{|c|c|c|}
\hline Result & No. of patients & Percentage \\
\hline Excellent & 5 & $27.7 \%$ \\
\hline Good & 8 & $44.4 \%$ \\
\hline Fair & 4 & $22.2 \%$ \\
\hline Poor & 1 & $5.6 \%$ \\
\hline
\end{tabular}

\section{Discussion}

Intra-articular pathology was found in patients on CT of type VI fractures where lateral condyle of tibia displaced lateral to lateral femoral condyle and associated with torn lateral meniscus for which lateral partial menisectomy done through arthrotomy.

Type I: fractures 1 in number $(5.6 \%)$ was operated because the displacement of articular surface was more than $2 \mathrm{~mm}$. The patient was of RTA. Postoperatively patients were immobilized in brace and active ROM started on third postoperative day and weight bearing is allowed as early as possible (avg. $10 \mathrm{wks}$ ). This patient achieved upto 90 degrees ROM without any deformity and good result.

Type II: fractures were 3 in number $(16.7 \%)$. one of these patients was operated with elevation of the depressed fragment, bone grafting and reduction of fracture and fixed with buttress plate. Those patients who had minimum displacement and communition, bone grafting was not done. Two of these patients had excellent results with full range of motion but one patient had valgus angulation with 0-90 range of motion.

Type III: fractures were present in 2 patients (11.1\%).Both of these patients were fixed with buttress plating with bone grafting. Both had up to 90 range of motion with one having valgus angulation. Both the patients showed good result.

Type IV: fractures were present 4 patients (22.2\%). These patients were operated with elevation of the medial plateau and fixed with buttress plate, locking plate and CC screw. These patients were mobilized late so as to prevent collapse of the fracture fragment and varus deformity. Two of these patients showed condylar widening of around $6 \mathrm{~mm}$.

Type V: fractures were 3 in number $(16.6 \%)$. Most of these fractures were displaced and comminuted. All of the patients were treated with buttress plate from one side, either medial or lateral depending on the communition with or without bone grafting. All patients showed good results with full range of motion.

Type VI: fractures were 5 in number $(27.7 \%)$. Most of these fractures were displaced and associated with high energy trauma with extensive soft tissue injuries. These patients were operated after 1 week when the skin condition improves.

Common modes of injury in this study were Road traffic accident $(80 \%)$, physical assault $(20 \%)$. This fracture usually occurs in middle and old age probably due to reduced strength of sub articular calcellous bone. In Rasmussen P.S. (1973) ${ }^{[26]}$ series average age was 55 years. In our study, average age was 40.2 years. Male of female ratio was 5:1 which corresponds to most of the series.

Antero-posterior, lateral and oblique x-rays are sufficient to diagnose the extent of depression, displacement and type of fracture. Tibial plateau view suggested by Moor T.M., Harvey J.P. (1974) is useful to evaluate the extent of depression. Stress X-rays (Forster E., Mole L.,Coblentz J. 1961, Martin A.F. 1960) are useful in diagnosis of ligamentous injury.

In our study we preferred SCHATZKER Classification because it is simple, uncomplicated and no special $\mathrm{x}$-rays required. Its practical utility to carry out treatment and prognosis has got an upper hand. Although Hohl's classification is detailed and excellent, it is complicated.

In Hohl M. and Luck J.V. (1956) ${ }^{[26]}$ series depressed type of fractures were $63.3 \%$. In our study, it was $11.1 \%$. According to Muller M.E., Allgower M. and Willengger H. type I is uncommon, but in our study it was 5.6\%. Type IV fracture is usually found in pure compression type of injuries. Type II and III are commonly found in old persons while type I and IV are commonly found in young patients

Frequency of involvement of right and left knee is same. In our study it was same. Lateral condyle is most commonly affected followed by medical condyle and finally bicondylar. (Hohl M. 1967). But in our study following Bicondylar fracture $(44.3 .3 \%)$ next in frequency was Lateral condyle fracture $(33.3 \%)$ and finally medial condyle (22.2\%).

In our study 18 patients were treated surgically. Indication of surgery was either depression or displacement Aim of Surgery was to achieve anatomical reduction, rigid internal fixation and early mobilization. Indication of surgery varies in different series.

We have followed AO Technique. LCP plates, Buttress plates and cancellous screws were used. For type II, III and IV bone grafts were used. Surgery requires skill, proper technique and instrumentation. Check x-rays were done before closing the wound, stability of the joint was tested. Associated ligamentous injury should be repaired at the time of Surgery. Knee bending was started after 72 hours, while mobilization with crutches was allowed after removal of stitches. Average duration of hospitalization was 21 days. It is because of high rate of post-operative wound infection $(33.3 \%)$.

Late valgus or varus deformities result from incomplete fracture reduction, collapse of soft cancellous bone beneath the articular surface during healing, or thinning of articular cartilage. Many patients with these deformities complain of pain in the medial side of the knee and required support at times. The long term effect of such deformities is posttraumatic arthritis. Genu valgus is observed commonly after central depression fractures which are treated conservatively. Stable tibial condyles, properly aligned on the femoral condyles are essential to prevent angular deformity of the knees. In our study angular deformity was present in 3 surgically treated patients ( 2 valgus and 1 varus) and five (5) 
conservatively treated patients (valgus).

Disabling pain years after a tibial condylar fracture is uncommon, although discomfort is noted frequently. Often the discomfort is on the medial side over the collateral ligament and is the result of chronic strain. Less often the pain is localized in the previously injured compartment of the knee and is caused by the traumatic arthritis that results from irregular surfaces, angular deformity, or degeneration of the articular surface. Prevention of late valgus or varus deformity seems essential to minimize the later development of knee pain from strain or traumatic arthritis. In our study, Pain at rest was present in one patient.

Partial weight bearing was started between 12 to 16 weeks. This corresponds to most of the series.

Results of treatment depends upon final outcome of the patients. Hohl M. and Luck J.V., $1956^{[26]}$, put forward excellent methods of grading the anatomical and functional results. Ramsussen method of grading is utilized in our study excluding the measurement of depression of tibial plateau in final results.

In our patients, acceptable results were obtained in $80 \%$ of patient (excellent $44.4 \%$ and good $38.8 \%$ ) which corresponds to series of Rasmussen P.S. (1973) ${ }^{[26]}$. Poor result was obtained in one patient who had type IV fracture with varus deformity of $10^{*}$, pain at rest, loss of $20 \mathrm{o}$ of extension (ROM 20-60o) and loosening of fixation. About $93.33 \%$ patients were satisfied with the final result, and resumed their duties. Only drawback of our treatment was long duration of hospitalization ( $\max 40$ days).

\section{Summary and Conclusion}

In our series type VI is the most common type of fracture pattern. Road traffic accidents are the main cause of injury with males affected more commonly than females. CT scan with three dimensional reconstructions gives accurate fracture geometry for preoperative planning for osteo-synthesis. Result of various types surgeries are good for various types of fracture pattern except when complications developed in elderly patients of type VI fracture pattern in the form of stiffness which led to an unacceptable outcome. It appears that all these problematic cases in the entire series belong to type VI group. So, alternative modality such as external fixator should be strongly considered for such a fracture pattern. Though locking compression plates are used in two of the patients, the results are same as the conventional plating but the numbers of cases in the series are insufficient to draw meaningful conclusion. Medial side buttress plating is always desirable in bicondylar fracture pattern with unstable medial condyle, to prevent delayed medial collapse and undesirable varus deformity.

\section{Figures}

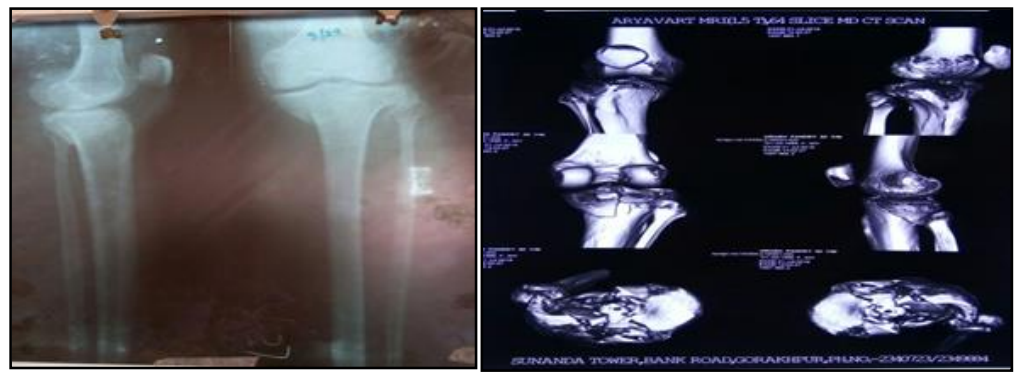

Fig 1: preop x-ray and CT

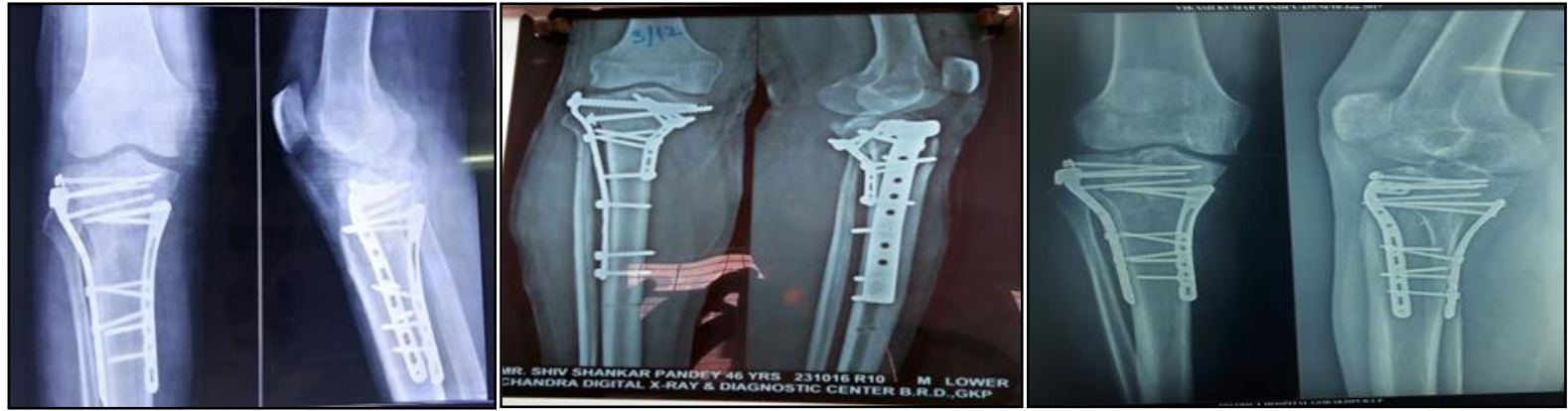

Fig 2: immediate post op and 3months and 6 months post op xray

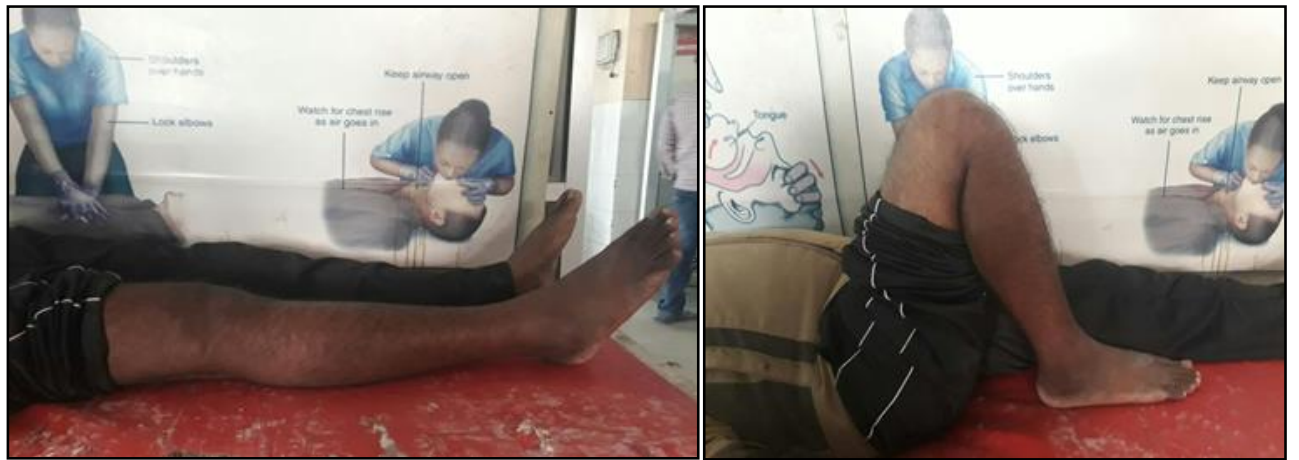

Fig 3: knee range of movement (full extension to 105 degree flexion) at 3 months 


\section{References}

1. Apley AG. Fractures of the lateral tibial condyle treated by skeletal traction and early mobilization. J.Bone Joint Surg. 1956; 38:699-708.

2. Delamarter R, Hohl M. The cast brace and tibial plateau fractures, Clin Orthop. 1987; 242:26.

3. Diass JJ, Stirling AJ, Finlay DBL, Gregg PJ. Computerised axial tomography for tibial plateau fractures, J Bone Joint Surg. 1987; 69:84.

4. Honkonen SE, Jarvienen MJ. Classification of fractures of tibial condyles, J Bone Joint Surg. 1992; 74:840.

5. Jensen DB, Rude C, Duus B, Bjerg-Nielsen A. Tibial plateau fractures. A comparison of conservative and surgical treatment. J Bone Joint Surg. 1990; 72:49-52.

6. Kennedy JC, Fowler PJ. Medial and anterior instability of the knee: an anatomical and clinical study using stress machines, J Bone Joint Surg. 1971; 53:1257-127.

7. Lansinger $\mathrm{O}$, Bergman B, Korner L, Anderson GBJ. Tibial condylar fractures: a twenty year follow up, J Bone Joint Surg. 1986; 68:13.

8. Mankin HJ. The response of articular cartilage to the mechanical injury: J Bone Joint Surg. 1982; 64:460-466.

9. Watson JT. High-energy fractures of the tibial plateau. Clin Orthop North Am. 1994; 25:723-52.

10. Musahl V, Tarkin I, Kobbe P. New trends and techniques in open reduction and internal fixation of fractures of the tibial plateau J Bone Joint Surg. 2009; 91:426-33.

11. Lubowitz JH, Elson WS, Guttmann D. Arthroscopic management of tibial plateau fracture part-I: Arthroscopy 2004; 20:1063-1070.

12. Marsh JL, Smith ST, Do TT. External fixation and limited internal fixation for complex fractures of the tibial plateau. J Bone Joint Surg. 1995; 77:661.

13. Fitdriyah Hussain, Mohammed Rafiq Abdul Kadir, Ahmad Hafiz Zulkifly, Azlin Sa'at, Azian Abd Aziz, Md Golam Hossain et al. Anthropometric Measurements of the Human Distal Femur: A Study of the Adult Malay Population. Hindawi Publishing Corporation, BioMed Research International, 2013: 175056:5. http://dx.doi.org/10.1155/2013/175056

14. Clyton Perry, Lawerence G. Evans, Samrile et al. A new surgical approach to fractures of lateral tibial plateau. J Bone Surg. 1984; 66:1236-1241.

15. Cubbins WR, Conley AH, Callahan JJ, Scuderi CS. Fractures of the lateral condyle of the tibia classification, pathology, and treatment, Surg. Gynecol. Obstet. 1934; 59:461-468.

16. Haldeman KO. The healing of joint fractures. A clinical and experimental study. J Bone Joint Surg. 1939; 20:912922.

17. Heppanstall RB. Fracture, healing and treatment. W.B. Saunders and Co. 1979, 735-745.

18. Muller ME, Nazarian S, Koch P, Schatzker J. The comprehensive classification of fractures of long bones. New York: Springer, 1990.

19. http://www.springer.com/us/book/9783642080913 Manual of Internal Fixation. Techniques Recommended by the AO-ASIF Group. Authors: Müller, M.E., Allgöwer, M., Schneider, R., Willenegger, H.

20. Watson JT, Schatzker J. Tibial plateau fractures. In: Browner BD, Jupiter JB, Levine AM, Trafton PG, editors. Skeletal trauma. Basic science, management, and reconstruction. Saunders; Philadelphia: 2003. 2074-2130.

21. Inoue G MD, Kuboyama K MD, Shido T MD. Avulsion fractures of the proximal tibial epiphysis: $\mathrm{Br} \mathrm{J} \mathrm{Sp} \mathrm{Med}$
1991; 25(1).

22. Hohl M, Luck JV. Fractures of the tibial condyles. A clinical and experimental study. J Bone Joint Surg. 1956; 38:1001-1018.

23. Hohl M. Tibial condylar fractures. J Bone Joint Surg, 1967; 49:1455-1467.

24. Hohl M, Robert Larson. Fractures and dislocations of the knee- Fractures by Rockwood \& Green: JB. Lippincott and Co. 1975; 2:1158-1178.

25. Kennedy WR. Fractures of tibial condyles - A preliminary report on supplementary fixation with methylmethocrylate. Clin. Orthop. 1978; 134:153-157.

26. Rasmussen PS. Tibial condylar fractures. J Bone Joint Surg. 1973; 55:1331-1350.

27. Slee GC. Fractures of the tibial condyles. J Bone Joint Surgy. 1955; 37:427-437.

28. Watson-Jones R. Fractures and Joint Injuries. ed. 4. Baltimore Williams \& Wilkins, 1955.

29. Rüedi TP, Sommer C, Leutenegger A. New techniques in indirect reduction of long bone fractures. Clin Orthop Relat Res. 1998; (347):27-34.

30. Bennett WF, Browner B. Tibial plateau fractures: a study of associated soft tissue injuries. J Orthop Trauma. 1994; 8(3):183-188. 